\title{
A Computational Simulation for the Damage Mechanism of Steel-Concrete Composite Slabs under High Cycle Fatigue Loads
}

\author{
Chikako Fujiyama ${ }^{1}$ and Koichi Maekawa ${ }^{2}$
}

Received 28 December 2010, accepted 21 March 2011

\begin{abstract}
This paper investigates the failure mode and the damage mechanism of steel-concrete composite slabs under high cycle fatigue loads by using three-dimensional nonlinear finite element analysis. The applicability of the simulation system, which was originally developed for reinforced concrete slabs, is extended to the steel-concrete composites with the proposed interface element, and experimentally verified with fatigue loading tests for bridge decks. The computed midspan deflection of composite slabs shows a fair agreement with data obtained from the experiment, and the horizontally induced cracking observed in reality is properly reproduced by the computational simulation. Finally, the authors predict the ultimate state at which the upper concrete layer separated by horizontal cracks fails in compression fatigue, and the corresponding S-N diagram is computationally predicted for the future discussion.
\end{abstract}

\section{Introduction}

\subsection{Background}

There have been a lot of damaged reinforced concrete (RC) bridge deck slabs reported in Japan since 1960. To work out the causes of this problem, different groups of researchers installed a wheel-type moving load testing machine (Maeda and Matsui 1984). Various experiments of slabs have been conducted since 1980 (Matsui 1987; Pedikaris and Beim 1989). Based upon the results of these experimental studies, they could arrive at several influencing factors in fatigue problems, such as minimum thickness of slabs, and a certain requirement of rebar arrangement to be renewed in national design codes.

Alternatively, recent developments in the field of computer simulation technology have led to renewed interest in fatigue problems. Theoretical model for fatigue of plain concrete based on damage mechanics were presented (Papa et al. 1996; Alliche 2004). Mesoscopic analyses using Rigid Body Spring Model were also developed for fatigue problems (Matsumoto et al. 2008), and that showed an agreement with the characteristics of cumulative damage of concrete observed by Oh et al. (1991). For the simulation of structural concrete, Peerapong and Matsumoto (2006) and Maekawa et al. (2006a, 2006b) demonstrated fatigue simulation of RC slabs by using FE analysis.

Furthermore, there has been a growing interest to utilize steel-concrete composites for bridge decks over the past decade. The reason is due to the reduced numbers of plate girders supporting bridge decks. It is of particular importance for use in a long span situation, where the use of RC slabs is unfeasible. The fatigue perform-

\footnotetext{
${ }^{1}$ Post doctoral fellow, The University of Tokyo, Japan. E-mail: fujiyama@concrete.t.u-tokyo.ac.jp

${ }^{2}$ Professor, The University of Tokyo, Japan.
}

ance of this newly innovated composite system has been confirmed by moving load tests (Public Works Research Institute of Japan 2001). It should be noted however that the tests were typically intended to verify the endurance limit of the composite system. No detailed investigations were conducted regarding the involved mechanism under fatigue loading as well as the ultimate strength. Therefore, a simulation system is required. This paper focuses on studying the fatigue mechanism of steelconcrete composite bridge deck slabs in high-cycle fatigue loading, and attention is directed to the characteristic cracking which is induced inside the composite slabs and not visible from outside.

\subsection{Direct path-integral scheme for high cycle fatigue load}

The fatigue simulation system used herein is based on the direct path integral scheme (Maekawa et al. 2003). The simulation is conducted by tracing the evolution of microscopic material states at each moment and location. In general, the whole hysteresis and progressive nonlinearity of consistent materials under high cycles of loading is followed up computationally with the high-speed multi-core processing technology. This finite element simulation uses three basic and essential constitutive models: compression, tension and crack shear transfer models along crack planes (Fig. 1).

The fatigue damage to concrete through compression and tension is taken into account by the constitutive law based on uni-axial fatigue tests (Tepfers 1979; Cornelissen et al. 1984). Concrete in compression not only undergoes plastic deformation but also gradually loses its elastic stiffness rooted in micro-cracks evolved in the concrete composite. This fatigue mechanism is expressed by the evolution law of the damage parameter denoted by $K$ (El-Kashif 2004) that includes effect of loading rate (Hsu 1981). The decrease in stiffness due to fatigue in the bond between reinforcement and concrete 


\begin{tabular}{|c|c|c|c|}
\hline & Compression model & Tension model & Crack shear model \\
\hline $\begin{array}{l}\text { Core } \\
\text { Constitu } \\
\text { tive low }\end{array}$ & 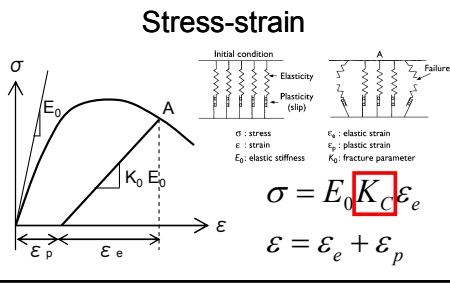 & 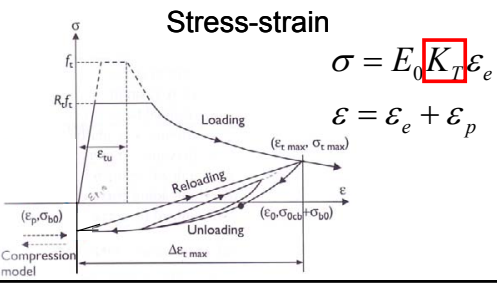 & Shear stress-shear strain \\
\hline $\begin{array}{l}\text { Enhanc } \\
\text { ed } \\
\text { model } \\
\text { for High } \\
\text { cycle } \\
\text { fatigue }\end{array}$ & $\begin{array}{l}\text { Fracture parameter Kc considers } \\
\text { time dependent plasticity \& } \\
\text { fracturing and cyclic fatigue } \\
\text { damage } \\
\qquad d K_{C}=\left(\frac{\partial K_{C}}{\partial t}\right) d t+\left(\frac{\partial K_{C}}{\partial \varepsilon_{e}}\right) d \varepsilon_{e} \\
\text { time dependent cyclic fatigue } \uparrow \\
\left(\frac{\partial K_{c}}{\partial \varepsilon_{e}}\right)=\lambda \sim \text { when } F_{k}=0 \\
\left(\frac{\partial K_{c}}{\partial \varepsilon_{e}}\right)=-\left(\frac{\partial F_{k}}{\partial \varepsilon_{e}}\right)\left(\frac{\partial F_{k}}{\partial K}\right)+\lambda \sim \text { when } F_{k}=0 \\
\frac{\lambda=K^{3} \cdot\left(1-K^{4}\right) \cdot g \cdot R}{\text { El-Kachif and Maekawa } 2004}\end{array}$ & $\begin{array}{l}\text { Fracture parameter } \mathrm{K}_{\mathrm{T}} \text { considers } \\
\text { time dependent fracturing and cyclic } \\
\text { fatigue damage } \\
\qquad K_{T}=F d t+G d \varepsilon_{e}+H d \varepsilon_{e} \\
\begin{array}{l}\text { Time dependent } \\
\text { fracturing }\end{array}\end{array}$ & 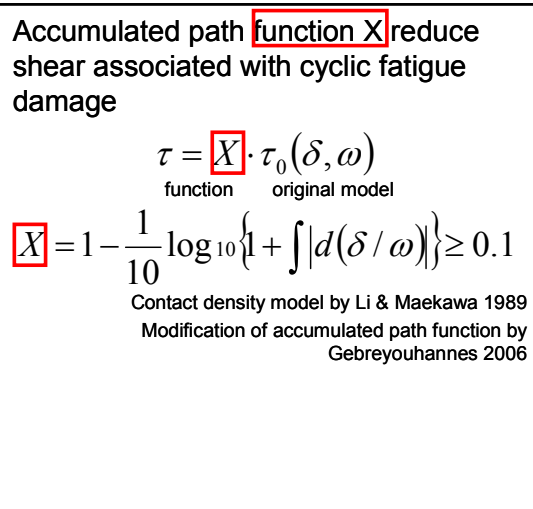 \\
\hline $\begin{array}{l}\text { Physical } \\
\text { meaning }\end{array}$ & $\begin{array}{l}\text { Decrease of stiffness and } \\
\text { plasticity accumulation by } \\
\text { continuous fracturing of concrete }\end{array}$ & $\begin{array}{l}\text { Decrease of tension stiffness by } \\
\text { bond fatigue }\end{array}$ & $\begin{array}{l}\text { Decrease of shear transfer normal to } \\
\text { crack by continuous deterioration of } \\
\text { rough crack surface }\end{array}$ \\
\hline
\end{tabular}

Fig. 1 Constitutive laws of concrete for high cycle fatigue analysis (Maekawa et al. 2006a).

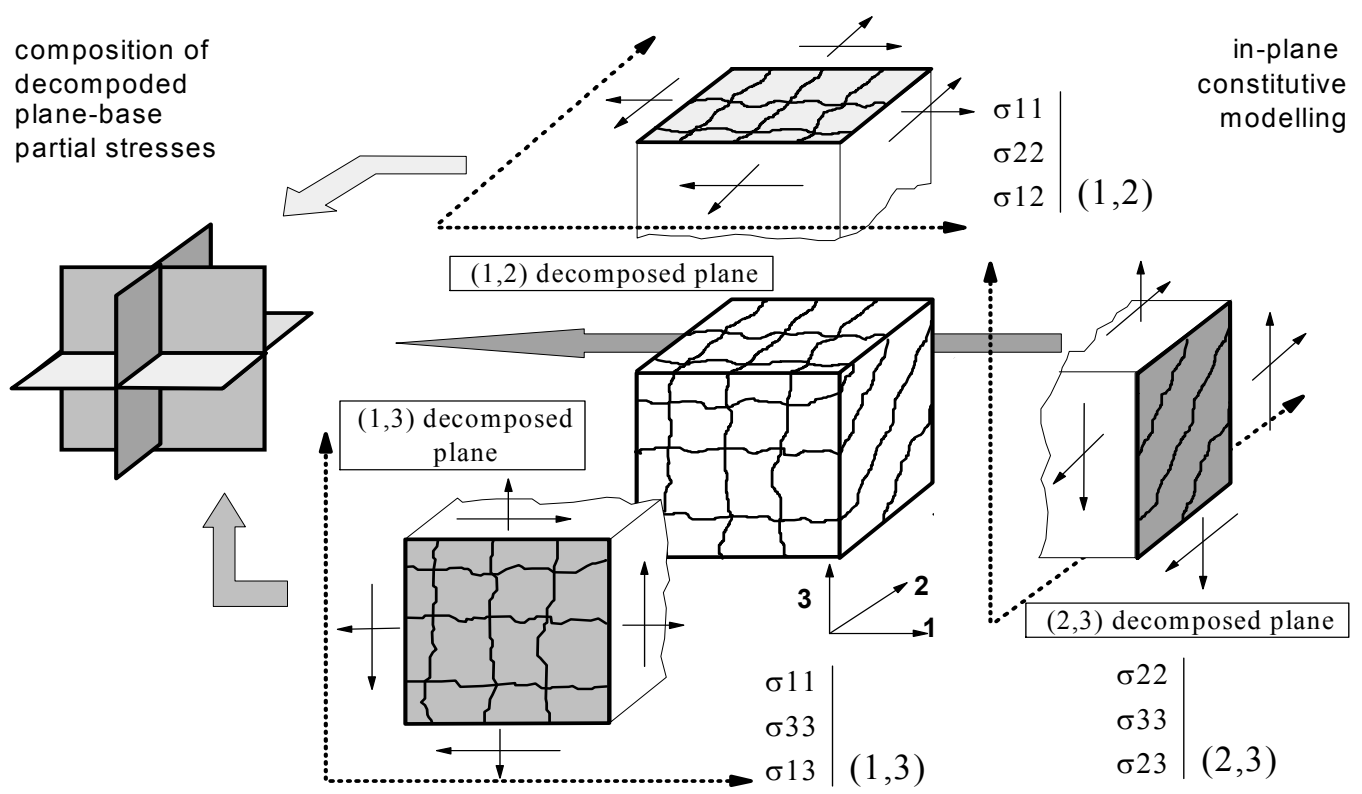

Fig. 2 Composition of sub-planes including non-orthogonal multi-directional cracks (Maekawa et al. 2003).

is reflected in the analysis as the damage parameter in progress on the tension side.

The crack plane of ordinary concrete exhibits roughness related to the size of suspended gravels. The roughness is scraped and smoothened under cyclic shear slip and the interlocking is gradually lost. In the shear transfer model stated previously, the term of damage is added to the original formulation so as to decrease the transferred shear according to the number of cycles represented by factor $X$ in Fig. 1.

In particular, to accelerate the computation especially for high cycle fatigue paths, the integral acceleration factor $\zeta$ is installed to the terms related to time and cumulative damage in these constitutive models 
(Maekawa et al. 2006a). After numerous cycles, the rate of nonlinearilty in progress becomes exponentially small. At this stage, the integral acceleration factor $\zeta$ magnifies the damage evolution in one step, which is equivalent to the damage caused by $\zeta$-cycles loading. This method enables to speed up high-cycle computation.

For 3D simulation, Maekawa et al. (2003) has extended in-plane 2D RC models including time dependent characteristics and creep models to a $3 \mathrm{D}$ orthogonal space system by means of the projection-composition method (see Fig. 2). This is regarded as an extended version of the smeared crack approach (Collins and Vecchio 1982), and the composition technique is regarded as a simple extension of the multi-directional non-orthogonal fixed crack modeling. This computational framework has already been verified under lowcycle static and dynamic loads (Maekawa et al. 2003). Whatever the complexity of the loading hysteresis is, the multi-axial stress-carrying mechanism is formulated as a simple summation of $1 \mathrm{D}$ sub-mechanisms representing the cracked concrete and reinforcement.

\subsection{Fatigue simulation of RC decks - Review -}

The simply supported RC slab subjected to moving wheel-type loads described by Maeda and Matsui (1984) was used for verification of the computational simulation. Here, no web reinforcement was considered in both experiment and analysis. In computation, 30 $\mathrm{N} / \mathrm{mm}^{2}$ was assumed as the uni-axial compressive strength of concrete and the high yield strength was assumed for reinforcement $\left(800 \mathrm{~N} / \mathrm{mm}^{2}\right)$ to prevent fatigue rupture of the steel. Analysis was carried out on a half domain of the slab with the x-coordinate (load travel direction) defined as the axis of symmetry as shown in Fig. 3 (Maekawa et al. 2006a).

Two types of load, cyclic fixed point loading and a traveling wheel-type one, were applied to allow for a comparison of failure mode and fatigue life as shown in Fig. 4, where the magnified displacement profile is inverted for ease of understanding. As a wheel-type load (tire) is not a concentrated sharp line but rather a belt action with breadth, forces are applied simultaneously on 6 adjacent nodal points on the central strip of finite elements, and the center of the resultant forces was gradually moved by shifting three sets of nodes on the loading FE strip. This results in a computed width of the wheel track of $173 \mathrm{~mm}$.

There was a great difference in failure modes with the two types of loading. Magnified modes of failure are shown in Fig. 4. For fixed-point loading, the so-called punching shear mode of failure is identical with the conical-shaped plane of failure (Higai 1978, Kakuta and Fujita 1982, Graddy et al. 2002) under concentric pulsation. Localized deformation of the slab in both longitudinal and transverse directions takes place and distinct concentrated downward displacement is visible at the center of the slab. In the case of moving loads, typical shear failure modes are not in evidence in the longitudinal direction of the slab (Fig. 4). This computational simulation was consistent with experimental observations.

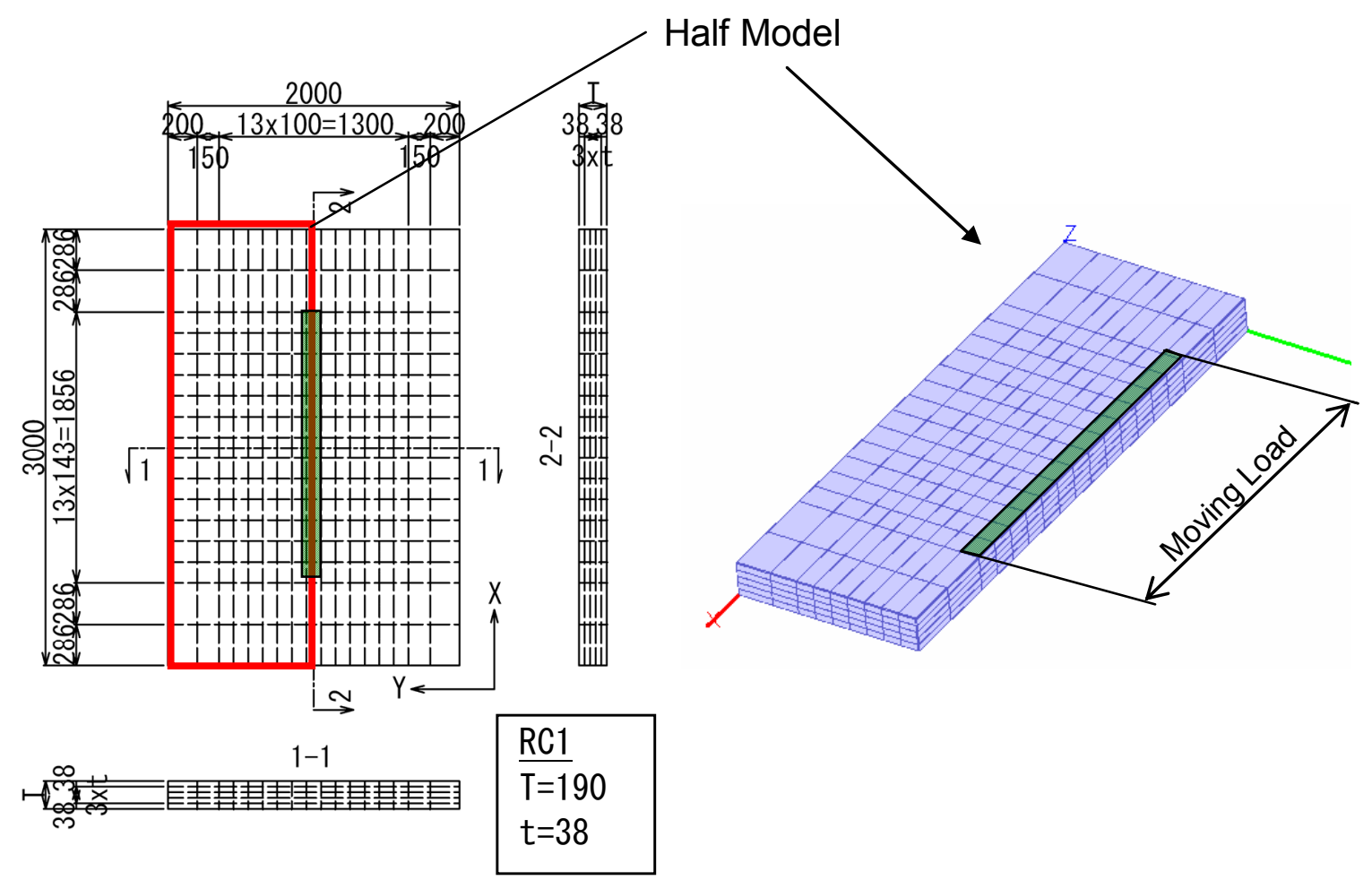

Fig. 3 RC bridge deck model. 


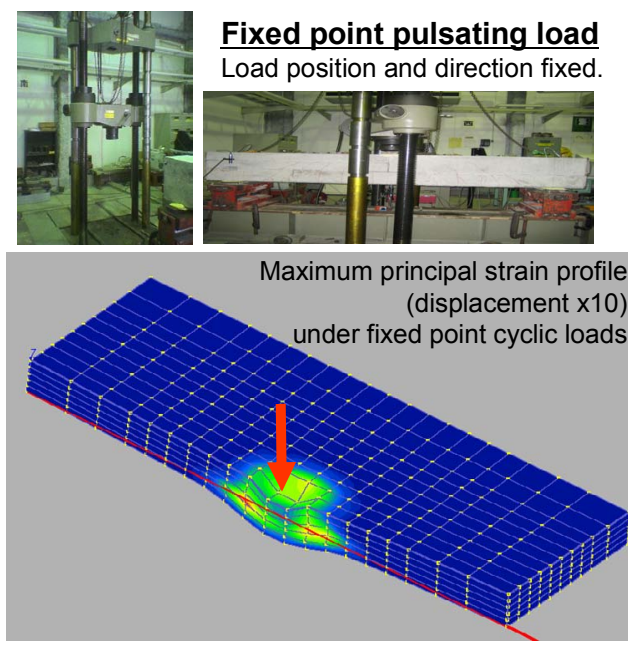

Damage and corresponding deformation are localized around the load point after many pulsating.

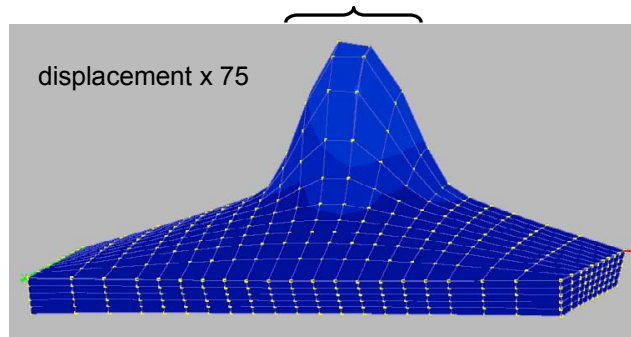

Magnified vertical displacement of the bottom face of the slab (upside down drawing)

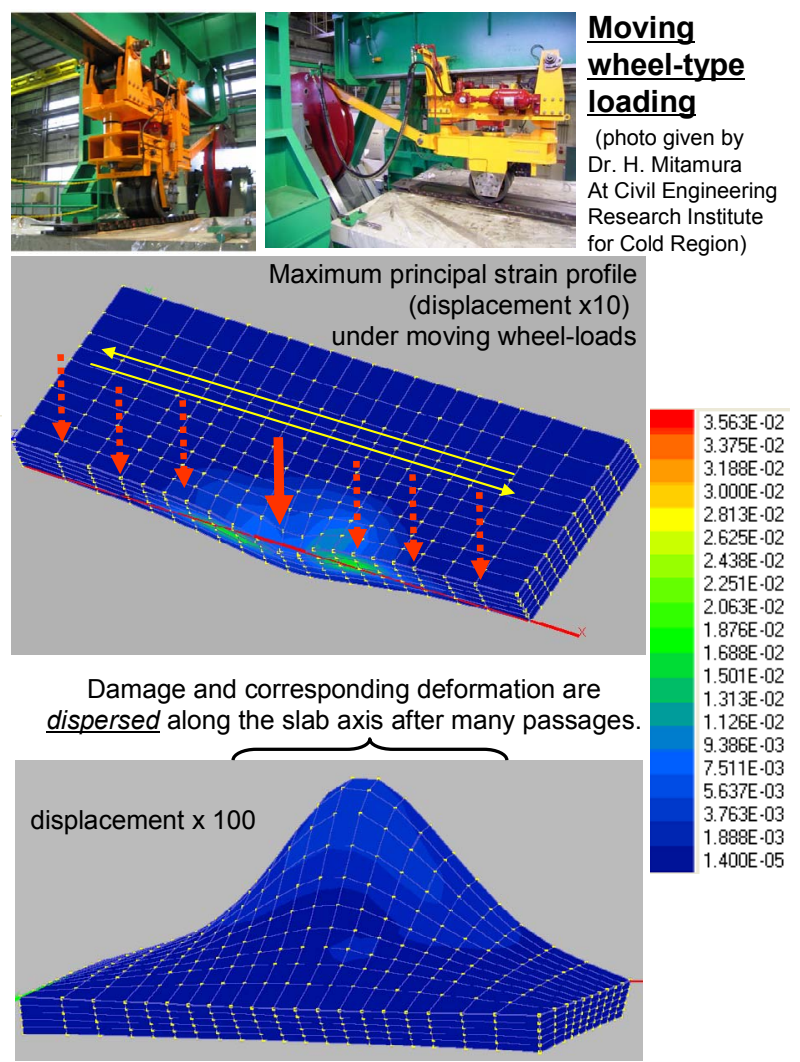

Damage and corresponding deformation are dispersed along the slab axis after many passages. $1.399 \mathrm{E} \cdot 02$
$1.167 \mathrm{E} \cdot 02$
$9.339 \mathrm{E} \cdot 03$
$7.011 \mathrm{E} \cdot 03$ 7.011E-03 $2.355 \mathrm{E} \cdot 03$ $2.700 \mathrm{E}-05$

Fig. 4 Magnified deformation under different types of loading (Maekawa et al. 2006b).
Under moving loads, multi-directional flexural cracks occur over the whole domain of the RC slab. Diagonal shear cracks in the longitudinal direction are prevented by crack-to-crack interaction (Pimanmas and Maekawa 2001). As a result, the load-carrying mechanism evolves from punching shear to semi in-plane load-carrying over the transverse direction. The three-dimensional direct path-integral scheme made it possible to reproduce the mechanistic character of failure modes and deformation.

In general, the S-N diagram is one of the most reliable methods for assessing RC bridge decks. Maekawa et al. (2006b) confirmed the S-N diagram for RC bridge

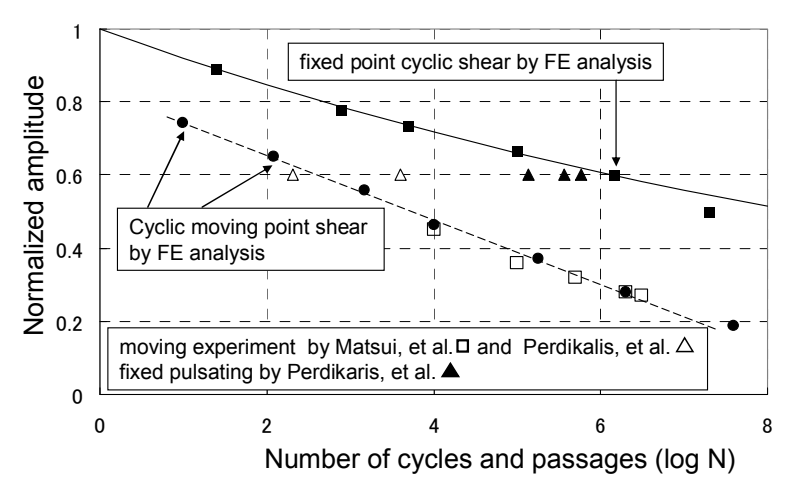

Fig. 5 S-N diagram for RC bridge deck.(Maekawa et al. 2006b). decks under both pulsating and moving loads by using the computational simulation (Fig. 5). Wheel-type loading considerably decreases the fatigue life of slabs. Roughly speaking, life is reduced by $1 / 100-1 / 1000$ in the computations, consistent with experimental observations. The high cycle fatigue analysis, using the logarithmic time-integral method, was introduced as one of the specific methods that enable the prediction of fatigue lives of full-scale RC slabs (Maekawa et al. 2006b).

\section{Extended model for Composite deck}

\subsection{Interface element between steel and con- crete}

To replicate the actual property between the steel plates and concrete, the interface element was considered (see Fig. 6). A state of free normal stress is assumed after debonding and separation. Afterwards, Mohr-Coulomb's law of friction is applied (Maekawa et al. 2008). A coefficient of friction, denoted by $\mu$, of 0.6 on average is assumed on the surface of contact (Rabbat et al. 1985). In this study, the authors consider the chemical adhesion of a steel-concrete interface as the initial bonding of 2.5 $\mathrm{MPa}$ according to the past experiences. The rigid stiffness of open-slip modes of the interface is assumed until the tensile stress normal to the interface may exceed the initial bonding. After de-bonding, Mohr-Coulomb's 
(1) Normal

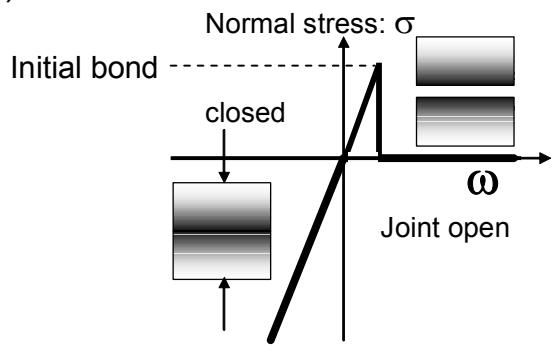

(2) Shear

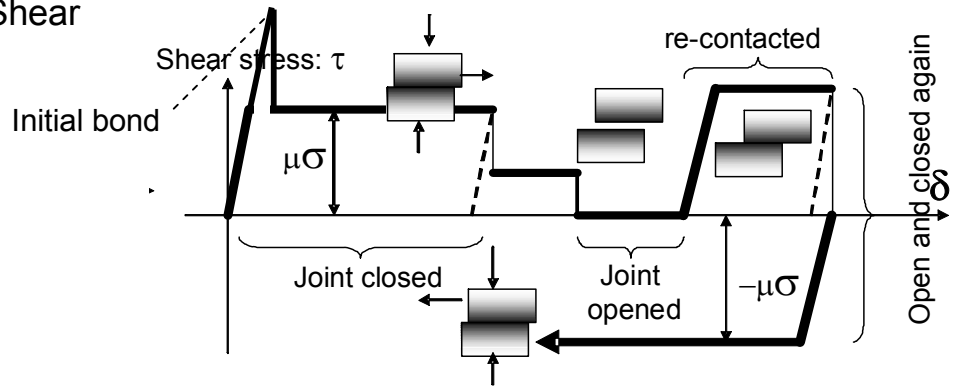

Fig. 6 Interface element model. frictional law is activated as stated above. No recovery of chemical adhesion is assumed. To simplify the model, the interface model does not take into account the change of the initially developed chemical bonding and the friction coefficient during the high-cycle fatigue in time domain.

\subsection{Examination of proposed interface element}

The interface element proposed above is examined against an experiment. First, a tested steel-concrete composite deck, which consists of the bottom plate, concrete slab and steel ribs as shear connectors, is shown with their material properties in Fig. 7. It is a 1.5 $\mathrm{m}$ square and the simply supported span is $1.2 \mathrm{~m}$. The steel ribs are spaced $300 \mathrm{~mm}$ apart. The spacing of reinforcing bars is $200 \mathrm{~mm}$ orthogonal to the ribs. The 169 $\mathrm{mm}$ total thickness includes the $9 \mathrm{~mm}$ thick bottom steel plate. The static loading area is $200 \mathrm{~mm}$ square at the center of slab.

The finite element discretization in space is shown in
Fig. 8. Solid isoparametric elements are used throughout the target structure. The nonlinear modeling for reinforced concrete and the plain one are described in the previous section. Reinforcing bars with surrounding concrete are modeled as a $35 \mathrm{~mm}$ thick reinforced concrete layer. The bottom plates and I-shape ribs are modeled as continuous elements with material properties of elasto-plasticity. All the surfaces of steel elements are covered by joint interface elements to connect with adjacent concrete. The total numbers of nodes are 12,450, and 8,400 solid elements and 2,030 joint interface ones are allocated in 3D extent.

Experimental data and simulated results are compared (see Fig. 9). Load versus mid-span deflection curves calculated by the analysis are almost consistent with experimental results. However, the maximum loadcarrying capacity in the analysis is slightly smaller than that obtained in the experiment. The crack profile at the mid-span cross section transverse to the rib direction is also compared with contour maps illustrated in the
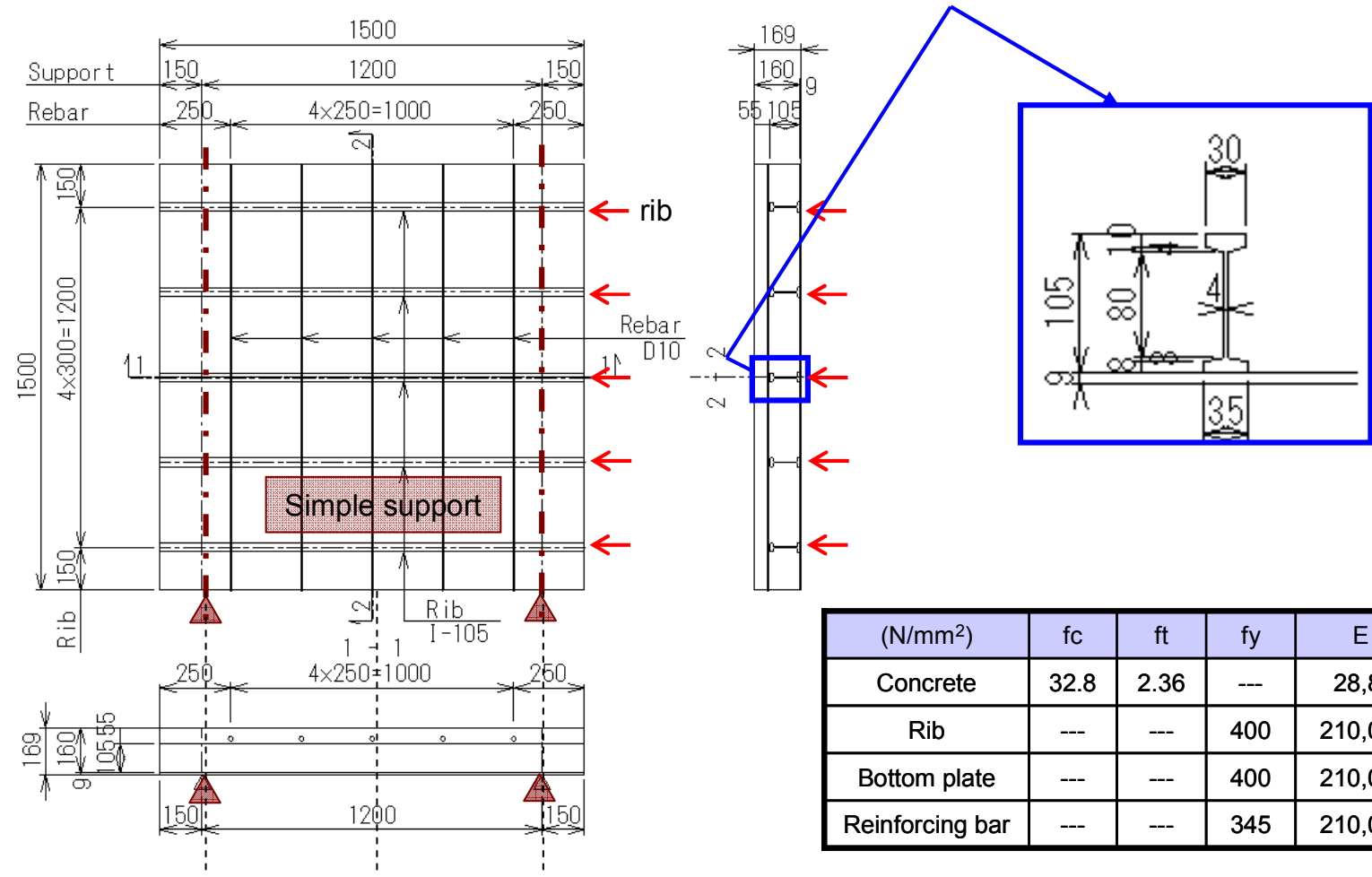

Fig. 7 Tested composite deck specimen. 


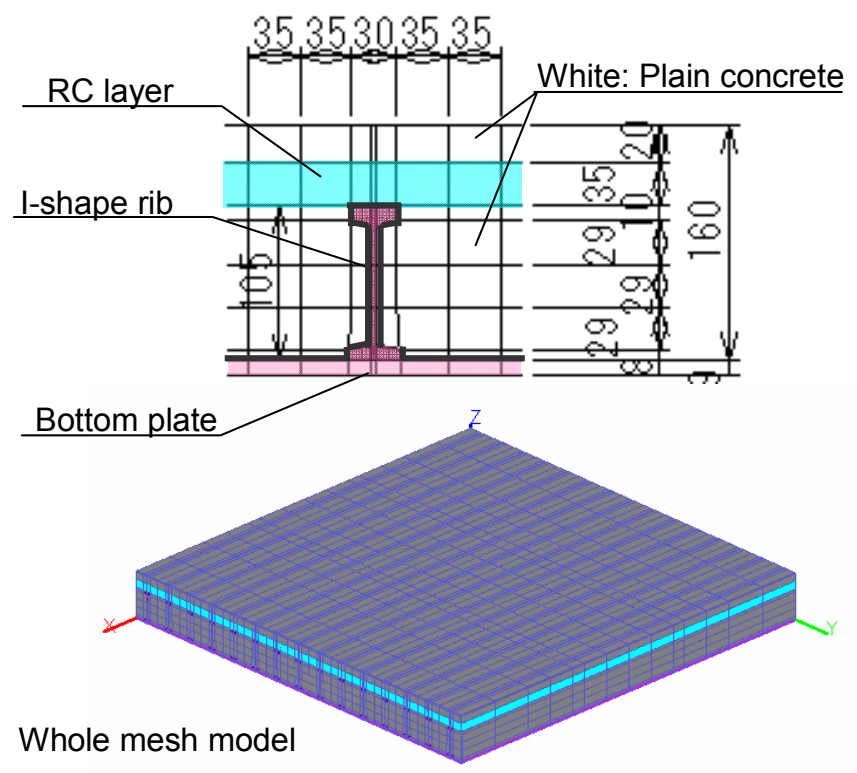

Interface element

(between steel and concrete)
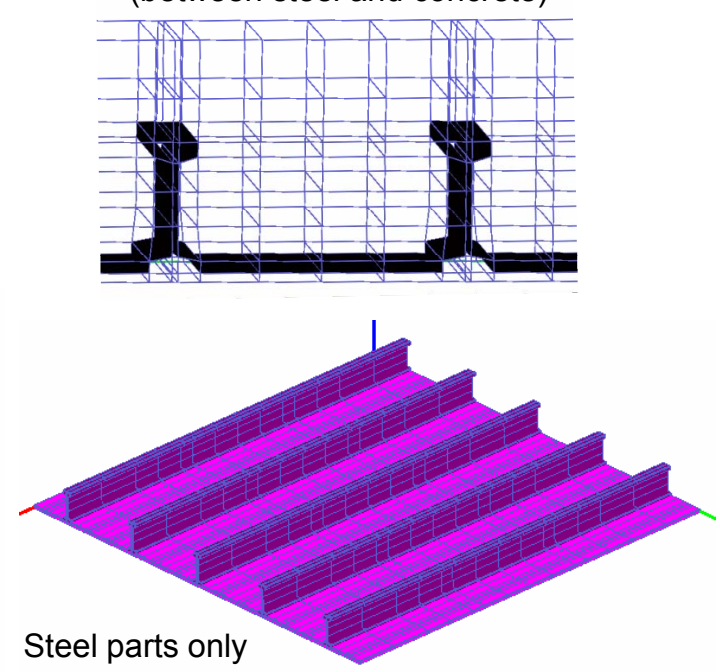

Fig. 8 FE mesh model of composite deck specimen.

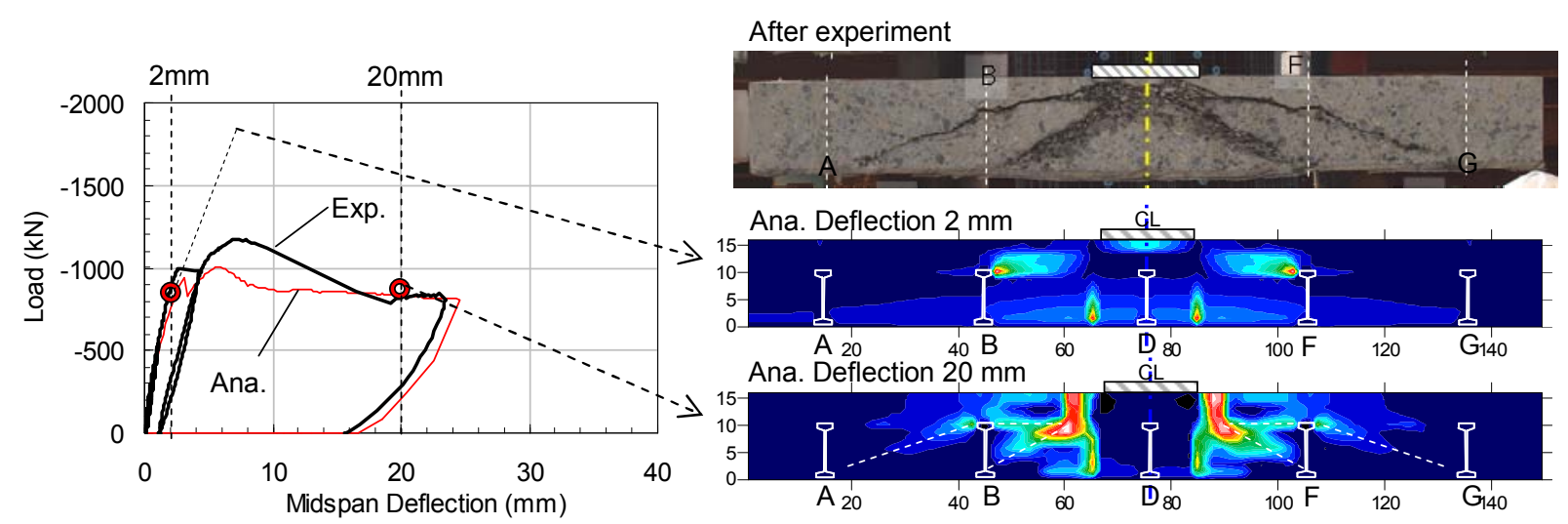

Fig. 9 Comparison experiment and analysis (Load versus mid-span deflection and crack profiles).

analysis. The photo shows two major cracks. One is the outer shear cracking that reaches via the tip of rib $\mathrm{B}$ and $\mathrm{F}$ to the root of rib $\mathrm{A}$ and $\mathrm{F}$ from the edge of loading plate, and another one is the inner shear crack that seems to be a typical punching shear crack. The contour map of $2 \mathrm{~mm}$ mid-span deflection shows the initiation of the outer shear crack from the tip of ribs, and the contour map of $20 \mathrm{~mm}$ mid-span deflection shows the propagation of both outer and inner shear cracks. These comparisons are thought to support the validity of the proposed interface model and the reproducibility of the finite element analysis.

\section{Fatigue simulation for composite deck under moving loads}

\subsection{Fatigue simulation: damaging process} (1) Model profiles and procedure of moving load in analysis

Using the interface element described above, the direct path-integral scheme, which was summarized in the previous section, is directly applied to the fatigue simulation of steel-concrete composite slabs under high cycle moving loads. The composite deck model investigated here faithfully follows the experimental study reported by Sakurai et al. (2005) (see Fig. 10). It consists of the bottom steel plate, I-shape steel, reinforcing bars and concrete. The plane dimensions of the slab are $2.4 \mathrm{~m} \times 4.5 \mathrm{~m}$ and $166 \mathrm{~mm}$ thick including a $6 \mathrm{~mm}$ thick bottom plate. I-shape steels in transverse direction are set ctc $200 \mathrm{~mm}$. Single layers of reinforcement consisting of D16 ctc $200 \mathrm{~mm}$ are provided on the I-shape ribs in the longitudinal direction. Because of its symmetry, only half of the slab is modeled in the analysis (see Fig. 10). Solid elements are used throughout for the model in which material property is presented in Table 1. Since the bottom plate and I-shape ribs were welded, they are modeled as continuous elements but with different material properties accordingly. All the surface of steel element is covered by interface element. The total num- 
Table 1 Material property of composite deck.

\begin{tabular}{|l|l|c|c|}
\hline \multirow{2}{*}{ Concrete } & \multicolumn{1}{|c|}{$\begin{array}{c}\text { Strength } \\
\mathrm{N} / \mathrm{mm}^{2}\end{array}$} & $\begin{array}{c}\text { Stiffness } \\
\mathrm{N} / \mathrm{mm}^{2}\end{array}$ & $\begin{array}{c}\text { Poisson's } \\
\text { ratio }\end{array}$ \\
\hline $\begin{array}{l}\text { Reinforcement } \\
\mathrm{fc}=36\end{array}$ & $\begin{array}{l}\text { Tension } \\
\mathrm{ft}=2.5\end{array}$ & $3.0 \times 10^{4}$ & 0.17 \\
bar (D16) & $\begin{array}{l}\text { Yield point } \\
\mathrm{fy}=400\end{array}$ & $2.0 \times 10^{5}$ & 0.30 \\
\hline Bottom plate & $\begin{array}{l}\text { Yield point } \\
\mathrm{fy}=350\end{array}$ & $2.0 \times 10^{5}$ & 0.30 \\
\hline I-shape rib & $\begin{array}{l}\text { Yield point } \\
\text { fy = 400 }\end{array}$ & $2.0 \times 10^{5}$ & 0.30 \\
\hline
\end{tabular}

bers of nodes are 18,580 , and 11,088 solid and 4,158 interface elements are arranged for the $3 \mathrm{D}$ analysis domain.

The moving point load rolls back and forth in a range of $3.0 \mathrm{~m}$, as is shown in Fig. 10, in both experiment and analysis. The travelling load pattern is produced in the analysis by applying linearly varying nodal forces in each load step with phase-shift along the wheel running line. As a result, the total nodal force is always kept constant during the passage of moving loads but the gravity center of the applied nodal forces moves step- by-step. The wheel load increases in increments of 19.6 $\mathrm{kN}$ every 40,000 passages from $157 \mathrm{kN}$ to $392 \mathrm{kN}$ so as to match the experiment conditions. Beyond 520,000 passages, fatigue analysis continues under the maximum loading of $392 \mathrm{kN}$. Figure 11 shows the step-wise incremental loading pattern versus the number of passages used in this analysis and experiment.

To obtain the progress of maximum and minimum mid-span deflections in experiments, the static load is applied at the center of the slab every 40,000 passages of the wheel loading. The minimum deflection means the residual one after complete unloading. The loading speed was also set forth consistently with the experimental condition. Then, the inertial forces and impact can be automatically taken into account in the simulation. In fact, the dynamic responses with inertia forces are generally different from the quasi-static responses in reality. It has been reported that the dynamic responses obtained in the past were about $10 \%$ larger than the static values (JSCE. 2008).

\section{(2) Progress of mid-span deflection and chemical bonding}

Figure 12 shows the progressing deflection at the span center and cyclic numbers from the analysis with different chemical bonding, together with experimental data

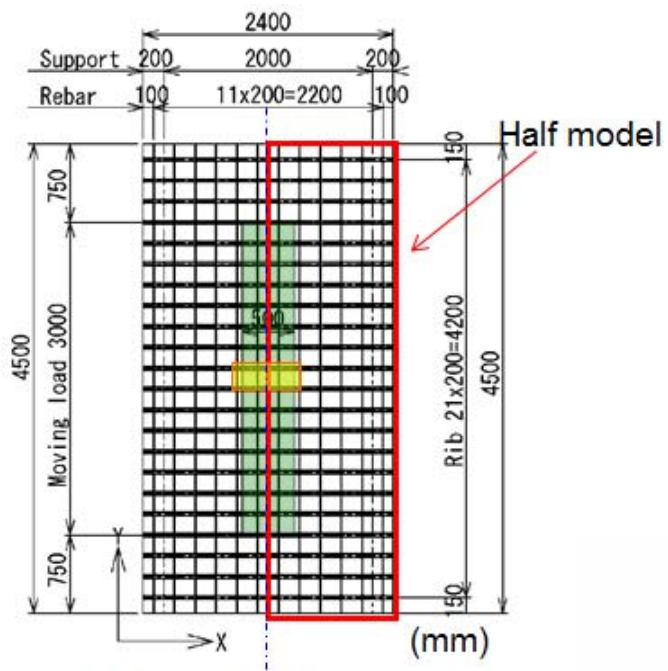

Tested composite deck specimen

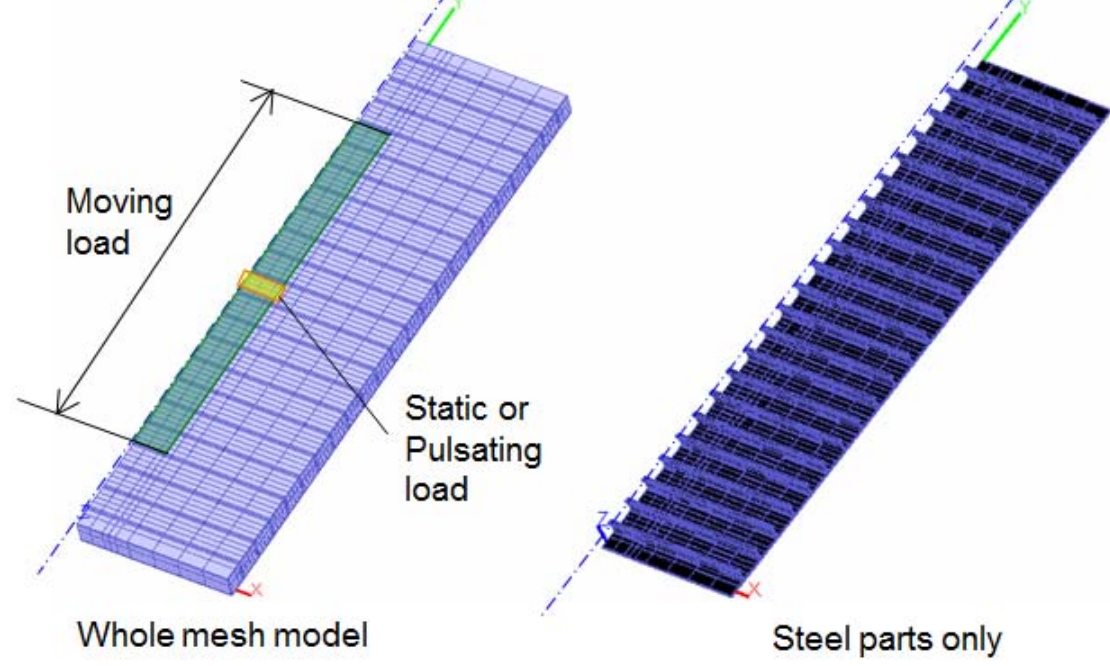

Fig. 10 The target composite deck model. 
by Sakurai et al. (2005). The overall trend is simulated successfully. The maximum deflection in the analysis with chemical bond of $2.5 \mathrm{MPa}$ is slightly underestimated (Fig. 12(a)). In contrast, the calculated maximum deflection assuming no chemical bond is larger than that of the experiment, and the residual deflection in the analysis is slightly higher than the experimental results up to about 200,000 passages (Fig. 12(b)). According to the material experiments and experiences in practice, the chemical bond strength ranges very widely (from zero to the level of tensile strength of concrete) and is much influenced by the local bleeding and consolidation of fresh concrete. In this experiment, 1.0 MPa seems to be close to the initial bond strength (Fig. 12(c)). Although it is hard to explicitly identify the realized chemical bonding strength inside the structure, it may be within the reasonable range according to the past experimental results.

\section{(3) Characteristic cracking from the tip of ribs}

A photo of the test specimen's cross section after the experiment is shown in Fig. 13. The horizontal cracks starting from the tip of steel ribs can be observed. To compare this failure mode with the analysis with the chemical bond of 1.0 MPa (Fig. 12(c)), the contour maps of vertical strains in the cross section (Y-Z section) at the center of the span at 320,000 passages and 520,000 passages are shown in Fig. 14. The vertical tensile strains of about $1,000 \mu$ or larger on average are concentrated in the concrete layer surrounding the upper flanges of the ribs, and the tensile strains extend horizontally (see Fig. 14(a)). This leads to the occurrence of cracking in the horizontal direction and the propagation of cracks between the upper flanges of the ribs (see Fig. 14(b)); that is to say, the damage process observed in the experiment is reasonably reproduced by the analysis. This failure mode is common to all cases with different chemical bonding.

To further analyze the mechanism by which cracks form and propagate in the horizontal direction, attention is focused on an element between the ribs at the center of the span (see Fig. 14). Calculated stress and strain of the referential element are shown in Fig. 15. Figure 15(a) indicates the tensile stress of the referential element in the vertical $(Z)$ direction with the number of passages. Vertical tensile stress actively responds and increases its amplitude up to 240,000 passages $(255 \mathrm{kN})$ and then stop increasing the positive stress thereafter, because the vertical stress of the referential element reaches the tensile strength of the concrete and cracks start at about 240,000 passages. Moreover, the strain of the referential element in the vertical $(\mathrm{Z})$ direction rapidly increases after 240,000 passages (Fig. 15(b)). This supports the finding that cracks start to open in vertical direction after this moment.

Figure 15(c) shows shear stress in the $X-Y$ plane in the referential element. The shear stress seems to decrease its amplitude after 360,000 passages. In contrast,

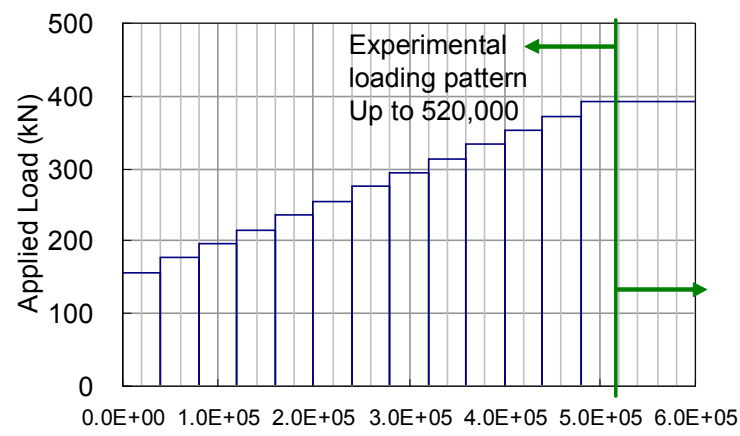

Number of passage

Fig. 11 Incremental loading pattern versus number of cycles.

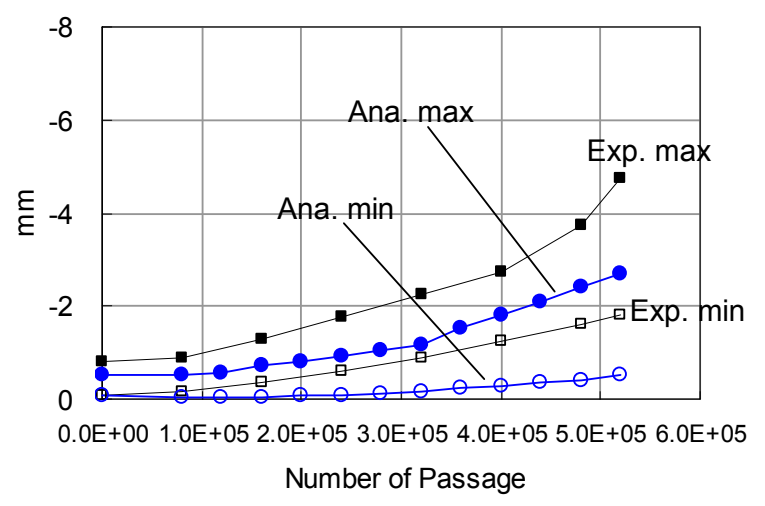

(a) With chemical bond of $2.5 \mathrm{MPa}$

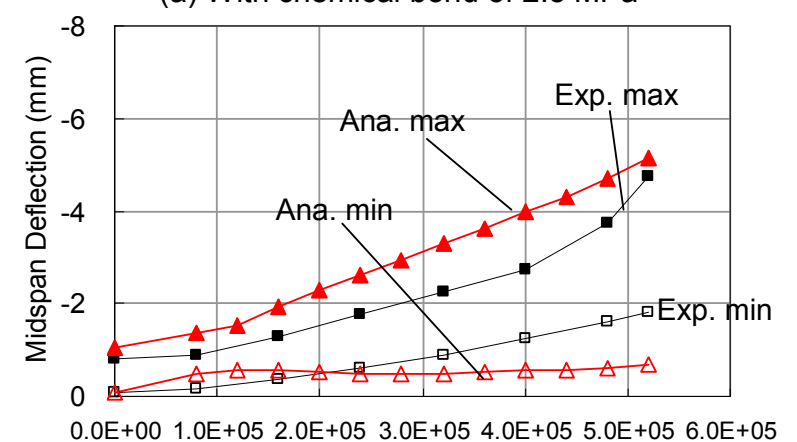

Number of Passage

(b) Without any chemical bond

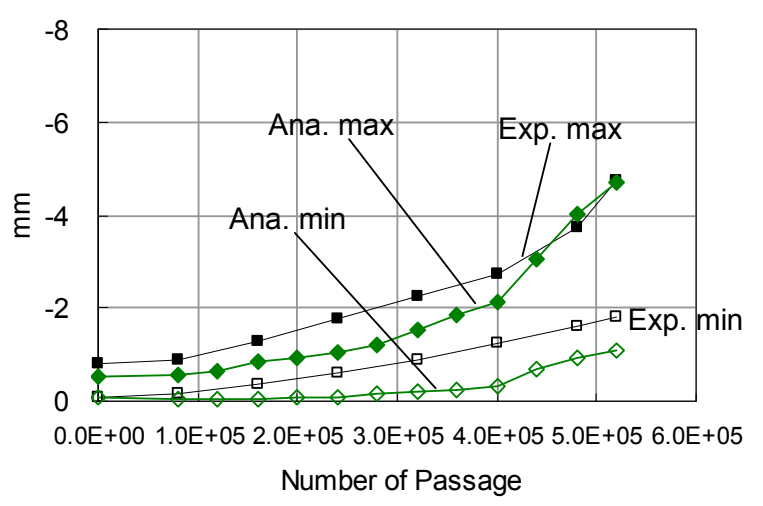

(c) With chemical bond of 1.0 MPa

Fig. 12 Progress of deflection at center of the deck with number of cycles. 

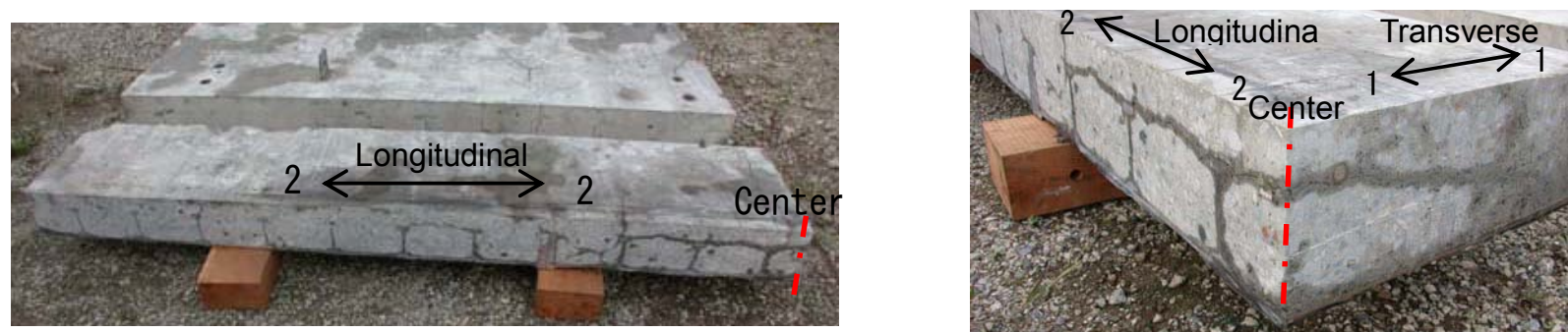

Fig. 13 Cracks observed after test (Sakurai et al. 2005).

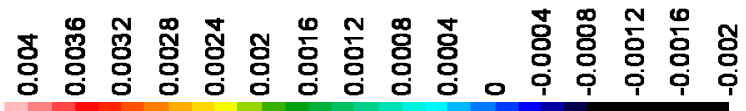

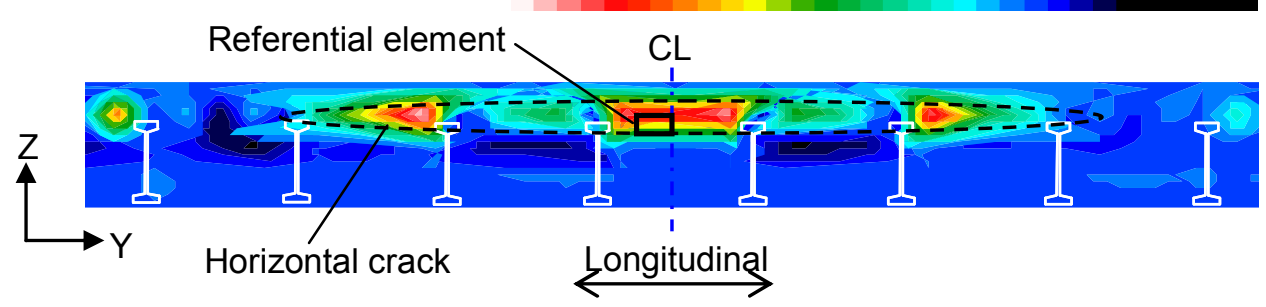

(a) after 320,000 passage

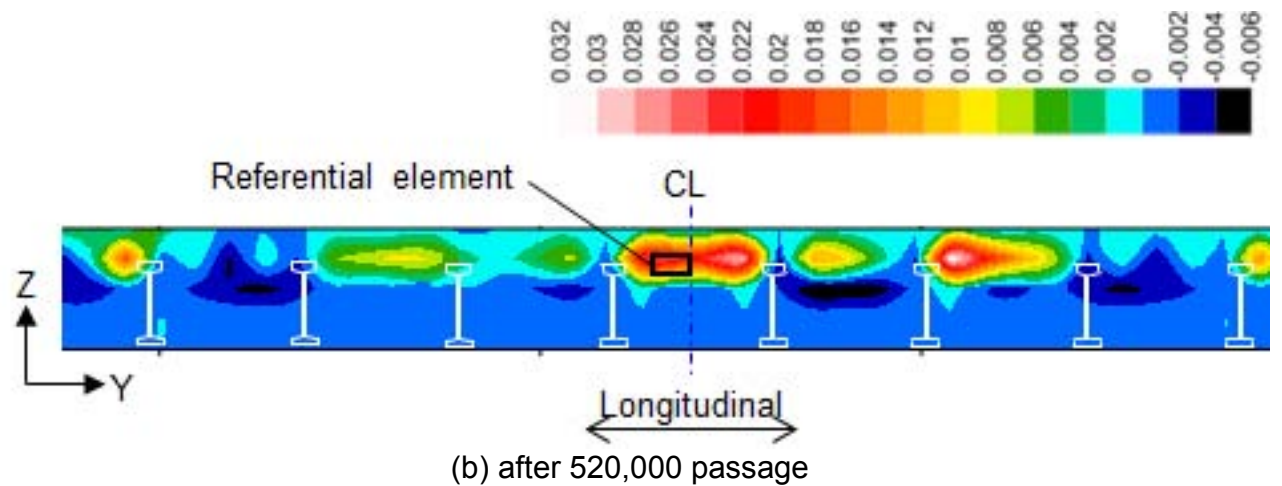

Fig. 14 Contour map of vertical strain.

shear strain gradually increases after about 400,000 passages $(314 \mathrm{kN})$ (Fig. 15(d)). This indicates that the horizontal cracking occurs at 240,000 passages, although it does not rapidly propagate to other elements. Each horizontal crack gradually spreads and connects with other adjacent cracks up to 360,000 passages. Even at this moment, however, the slab sustains load and the midspan deflection does not obviously increase (see Fig. 12(c)). The obvious increase of mid-span deflection can be seen after 400,000 passages (see Fig. 12(c)). The possible explanation is that even if horizontal cracks become partially connected, the integrity of the slab is not suddenly lost because of the interlocking effect at the cracked surface of concrete. The whole damage process indicated in the analysis seems to be reasonable.

\subsection{Fatigue life prediction: predicted ultimate limit state}

Once the number of passages reaches 520,000, at which the experiment was over, the analysis continues under constant moving wheel loading of $392 \mathrm{kN}$. The simulation reproduces the moving load continuously applied until failure without unloading process. Figure 16 shows the dynamic deflection response, which is simulated by assumption of a chemical bond of $1.0 \mathrm{MPa}$, with the number of passages. The analysis predicts that deflection increases monotonously on a logarithmic scale after the 520,000-passage point under the constant load of $392 \mathrm{kN}$.

Figure 17 shows the overall deformation of the slab at the maximum dynamic deflection of about $7 \mathrm{~mm}$ and $10,000,000$ passages. Although there is no observed punching shear failure, localized deformation is noted in concrete near the zone where the moving wheel load acts. The analysis infers the following damage mechanism (scenario): cracks are formed from the tip of the ribs and these connect over the whole slab after cyclic loading, dividing the concrete slab into two layers; in 


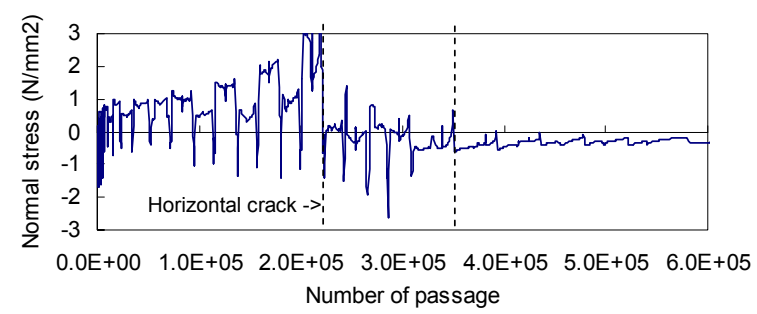

(a) Vertical stress in the element

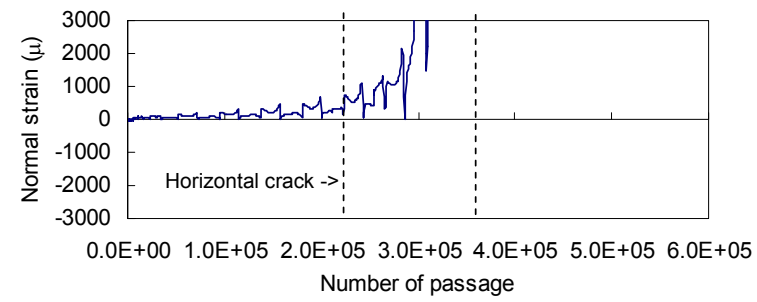

(b) Vertical strain in the element

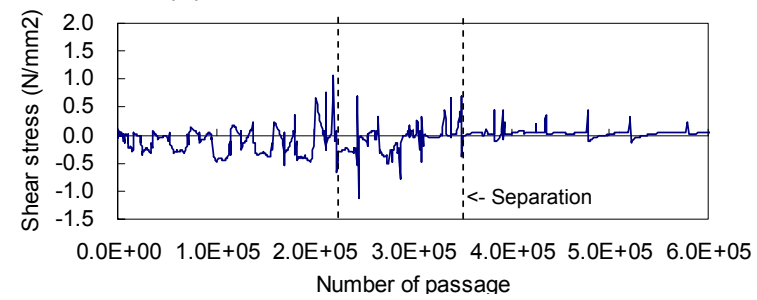

(c) Shear stress in the $X-Y$ section

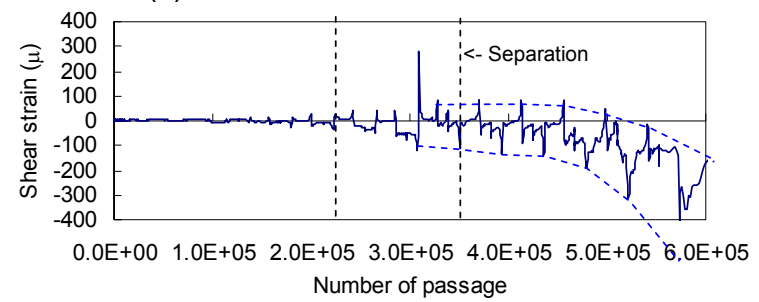

(d) Shear strain in the $X-Y$ section

Fig. 15 Changes in stress and strain in the element under focus with number of cycles.

the ultimate state, the concrete in the upper layer undergoes compression fatigue failure and the entire slab loses stiffness. The failure mode predicted in the analysis is the compression fatigue failure instead of punching shear failure or yielding of steel. The tensile stress in the bottom steel plate is $212 \mathrm{~N} / \mathrm{mm}^{2}$, and the steel does not yield at this moment.

For further understanding, the numerical approach is extended to the fatigue life assessment of steel-concrete composite slabs in terms of S-N diagrams. By considering the past criterion in practice, the amplitude of fatigue loading should be classified by the static loadcarrying capacity. Thus, the static analysis is carried out as a preparation for $\mathrm{S}-\mathrm{N}$ diagrams. The finite element analysis model is the same as shown in Fig. 10, and the chemical bond in this static analysis is $1.0 \mathrm{MPa}$ on average. The area on which the static loading is applied is $200 \mathrm{~mm}$ wide in the longitudinal direction and $500 \mathrm{~mm}$ long in the span direction of the slab $(200 \mathrm{~mm}$ by 250

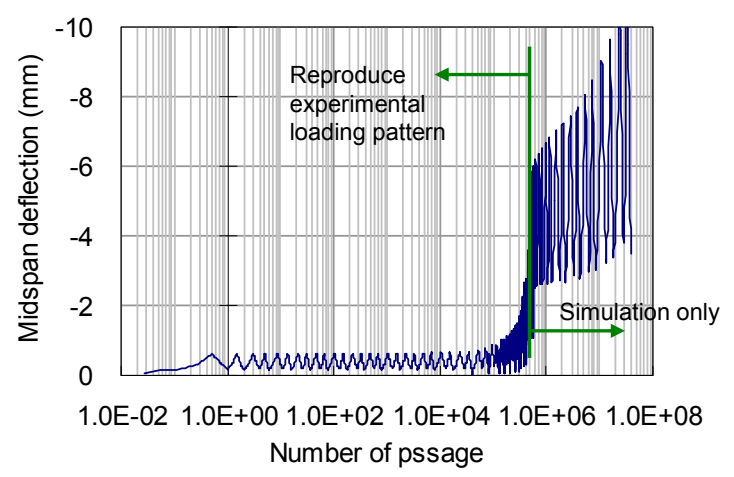

Fig. 16 Change in deflection at center of the deck with number of cycles (dynamic response).

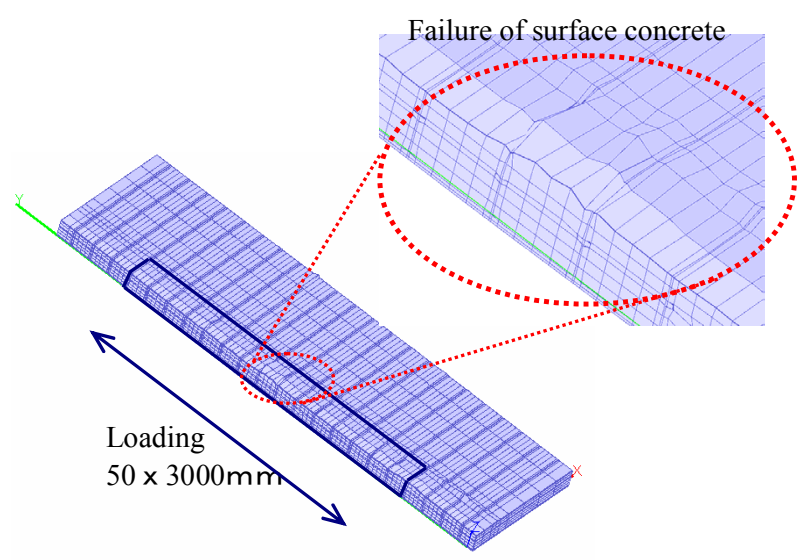

Fig. 17 Deformation at 10,000,000 cycles (displacement scaled up two times).

$\mathrm{mm}$ in the half model). The static force is applied by means of the forced nodal displacement control, and the pulsating load is produced by linearly varying nodal force in the analysis. The load versus deflection curve at the center of the slab is shown in Fig. 18. The computed maximum load-carrying capacity and the deflection at this maximum loading are about $1,514 \mathrm{kN}$ and $19.4 \mathrm{~mm}$, respectively. As a result of this preliminary analysis, the fatigue life is hereafter defined as the number of passages at which the center deflection of the slab reaches the one corresponding to the static capacity as $19.4 \mathrm{~mm}$. This definition is the same as that applied for the fatigue experiments of slabs.

The S-N diagram of the slab under the fixed-point cyclic loading and the moving wheel cyclic loading are shown in Fig. 19. The location and area of fixed-point loading are the same as the static analysis. The vertical axis is the amplitude normalized by the computational static capacity. The minimum load was set as zero. The blue line in the figure represents the formula of the fatigue life of slabs given by the Standard Specifications of Concrete Structures of the Japan Society of Civil Engineers (JSCE, 2008), assuming that the bottom steel plate forms part of the effective quantity of reinforce- 


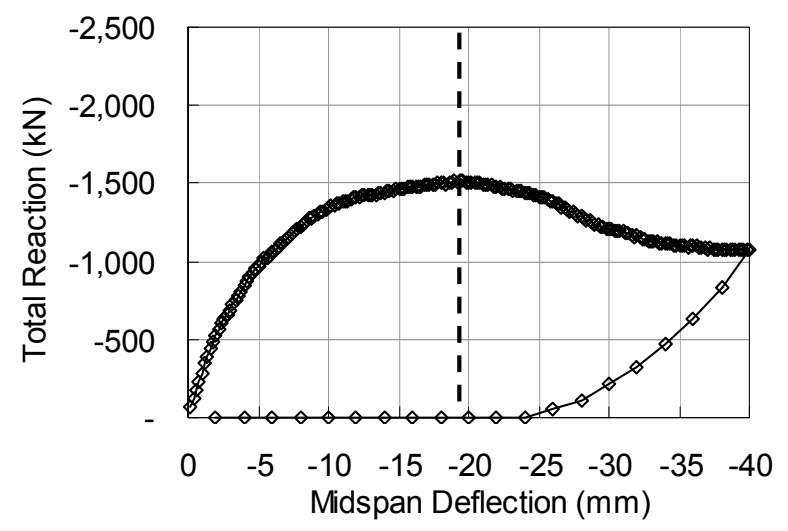

Fig. 18 Load -deflection at center of the deck (static analysis).

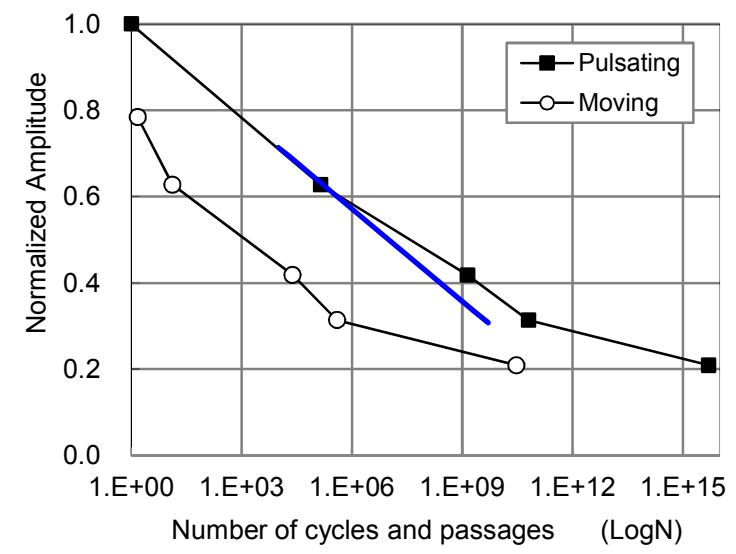

Fig. 19 Evaluation of composite decks under fixed-point loading and moving wheel loading.

ment in RC slabs. The arrow on the figure means that the specimen survives more than the plotted number of cycles.

Under fixed-point loading, the fatigue life at the higher amplitude agrees with the line given by the formula. This implies that the failure mode of the composite deck at high amplitudes is the same as that of RC slabs. In contrast, the fatigue lives at the lower amplitude tend to be longer than that given by the JSCE formula. This implies that the failure mode of the composite deck at low amplitudes might be different from the punching shear, which comes into sight at relatively high amplitudes.

All the fatigue lives investigated in this study under moving loading are significantly shorter than that under the fixed-point loading. This was expected based on the past experinetal and analytical studies on RC slabs (Matsui 1987; Pedikaris and Beim 1989). But, four or five order difference was much larger than the past experiences. As described before, the mechanism that shortens the fatigue life of the composite slab under heavy moving loading is the separation of concrete into two layers as a result of horizontal cracking. The separation caused by the horizontal cracks leads to the fatigue failure of the upper layer concrete. This indicates that the failure mode affects the fatigue life. Moreover, the failure mode of composite structures is greatly influenced by the mechanical property of shear connectors (Hawkins and Mitchell, 1984), because shear connectors can be a cause of cracking inside concrete. Further experimental and analytical investigations are needed to examine this issue.

\section{Conclusions}

1. RC and steel-concrete composite bridge deck slabs are simulated with full $3 \mathrm{D}$ nonlinear finite element analysis.

2. For the analysis of a steel-concrete composite structure, the interface element between concrete and steel members is defined based on Coulomb's friction law with chemical adhesion as an initial bonding strength.

3. The interface element proposed above is examined against an experiment. The comparisons of experiment and simulation are thought to support the validity of the proposed interface model and the reproducibility of the finite element analysis.

4. The progress of mid-span deflection under a high cycle moving load is successfully reproduced by analysis with the proposed interface element. Furthermore, horizontal cracks starting from the tip of Ishape steel can also be successfully reproduced in the simulation.

5. The analysis indicates that even after horizontal cracks formed, the slab can still partly sustain a moving load because of the inter-locking of the rough crack surface. This mechanism is gradually lost due to repetitive moving loads. As a result, concrete is separated into two layers.

6. More importantly, the ultimate state of the composite slab, where the upper layer concrete fail in compression fatigue, is predicted by analysis.

7. The S-N diagram of composite slab is shown based upon numerical analyses in this study.

\section{Acknowledgments}

The authors express their gratitude to Mr. N. Sakurai, the manager of the steel structure center of NIPPON STEEL ENGINEERING Co., Ltd, for providing photos and experiment information, and to Dr. B. Suryanto, Post-doctoral fellow of the University of Tokyo for valuable discussions. This study was financially supported by JSPS Grant-in-Aid for Scientific Research (A) No. 80157122, JSPS Grant in Aid for research fellowship for young scientists No.20-56191 and Ministry of Land, Infrastructure, Transport and Tourism Japan.

\section{References}

Alliche, A., (2004). "Damage model for fatigue loading of concrete." International Journal of Fatigue, 26, 915-921. 
Collins, M. P. and Vecchio, F., (1982). "The response of reinforced concrete to in-plane shear and normal stresses." University of Toronto.

Cornelissen, H. A. W. and Reinhardt, H. W., (1984). "Uniaxial tensile fatigue failure of concrete under constant-amplitude and program loading." Magazine of Concrete Research, 36(129), 216-226.

El-Kashif, K. F. and Maekawa, K., (2004). "Timedependent nonlinearity of compression softening in concrete." Journal of Advanced Concrete Technology, 2(2), 233-247.

Graddy, J. C., Kim, J., Whitt, J. H., Burns, N. H. and Klingner, R. E., (2002). "Punching-shear behavior of bridge decks under fatigue loading." ACI Structural Journal, 99(3), 257-266.

Hawkins, M. N. and Mitchell, D., (1984). "Seismic response of composite shear connectors." Journal of Structural Engineering, ASCE, 110(9), 2120-2136.

Higai, T., (1978). "Fundamental study on shear failure of reinforced concrete beams." Transactions of the Japan Society of Civil Engineers, 10, 339-343.

Hsu, T. T. C., (1981). "Fatigue of plain concrete." ACI Journal, 88(4), 292-304.

JSCE, (2008). "Required performance and maintenance technology for bridge slab." Tokyo: Sub-committee of Japan Society of Civil Engineers on Investigation for Bridge Slabs. (in Japanese)

Kakuta, Y. and Fujita, Y., (1982). "Fatigue strength of reinforced concrete slabs failing by punching shear." Transactions of the Japan Society of Civil Engineers, 14, 436-438.

Maeda, Y. and Matsui, S., (1984). "Fatigue of reinforced concrete slabs under trucking wheel load." Proceedings of JCI, 6, 221-224. (in Japanese)

Matsui, S., (1987). "Fatigue strength of RC-slabs of highway bridge by wheel running machine and influence of water on fatigue." Proceedings of JCI, 9(2), 627-632. (in Japanese)

Maekawa, K., Pimanmas, A. and Okamura, H., (2003). Nonlinear Mechanics of Reinforced Concrete. London: Spon Press

Maekawa, K., Toongoenthong, K., Gebreyouhannes, E. and Kishi, T., (2006a). "Direct path-integral scheme for fatigue simulation of reinforced concrete in shear." Journal of Advanced Concrete Technology, 4(1), 159-177.

Maekawa, K., Gebreyouhannes, E., Mishima, T. and An, X., (2006b). "Three-dimensional fatigue simulation of RC slabs under traveling wheel-type loads."
Journal of Advanced Concrete Technology, 4(3), 445457.

Maekawa, K., Fukuura, N. and Soltani, M., (2008). "Path-dependent high cycle fatigue modeling of joint interfaces in structural concrete." Journal of Advanced Concrete Technology, 6(1), 227-242.

Matsumoto, K., Sato, Y., Ueda, T. and Wang, L., (2008). "Mesoscopic analysis of mortar under high-stress creep and low-cycle fatigue loading." Journal of Advanced Concrete Technology, 6(2), 337-352.

Oh, B. H., (1991). "Cumulative damage theory of concrete under variable-amplitude fatigue loadings." ACI Materials Journal, 88(1), 41-48.

Papa, E. and Taliercio, A., (1996). "Anisotropic damage model for the multiaxial static and fatigue behaviour of plain concrete." Engineering Fracture Mechanics, 55(2), 163-179.

Pedikaris, P. C. and Beim, S. R., (1989). "RC bridge decks under pulsating and moving load." Journal of Structural Engineering, 114(3), 591-607.

Perdikaris, P. C., Beim, S. R. and Bousias, S. N., (1989). "Slab continuity effect on ultimate and fatigue strength of reinforced concrete bridge deck models." ACI Structural Journal, 86(4), 483-491.

Peerapong, S. and Matsumoto, T., (2006). "Fatigue analysis of RC slabs and repaired RC slabs based on crack bridging degradation concept." Journal of Structural Engineering, 132(6), 939-948.

Pimanmas, A. and Maekawa, K., (2001). "Finite element analysis and behaviour of pre-cracked reinforced concrete members in shear." Magazine of Concrete Research, 53(4), 263-282.

Public works research institute of Japan. (1999-2001). "Cooperative research on developing the evaluation method of fatigue durability of highway bridge slabs by wheel running machine test (Vol.1-Vol.5)." Tokyo: Public works research institute of Japan (in Japanese)

Rabbat, B. G. and Russell, H. G., (1985). "Friction coefficient of steel on concrete or gorout." Journal of Structural Engineering, 111(3), 505-515.

Sakurai, N., Fujikawa, K., Mizukami, S., Matsui, S. and Nagai, M., (2005). "A study on rationalization of the shape steel bridge." Structural Mechanics and Earthquake Engineering, 794, I-72, 67-86. (in Japanese)

Tepfers, R. and Kutti, T., (1979). "Fatigue strength of plain, ordinary, and lightweight concrete." $A C I$ Journal, 76(5), 635-652. 